\title{
Bipolar radiofrequency ablation for left ventricular aneurysm-related ventricular arrhythmia
}

\author{
Yang Yu, MD, PhD, Ming-xin Gao, MD, Chuan Wang, MD, and Cheng-xiong Gu, MD, Beijing, China
}

Surgery is an effective treatment for left ventricular aneurysm (LVA). However, sudden cardiac death caused by malignant ventricular arrhythmia (VA) occurring between 30 days and 5 years postoperation accounts for $29.6 \%$ and $36.8 \%$ of the total deaths recorded, respectively. ${ }^{1}$ Radiofrequency ablation is commonly used for treating VA. ${ }^{2}$ We report a patient with ventricular tachycardia who underwent LVA repair and bipolar radiofrequency ablation with good preliminary efficacy.

\section{CLINICAL SUMMARY}

A 53-year-old man with a history of diabetes mellitus and myocardial infarction was referred for cardiac surgery for unstable angina. His cardiac function was New York Heart Association grade IV. Coronary angiography showed triplevessel lesions. Echocardiography revealed paradoxical cardiac movements of the left ventricle in the systolic phase, a left ventricular ejection fraction of 0.32 , and a left ventricular end-diastolic diameter of $60 \mathrm{~mm}$. The LVA was located in the apex of the left ventricle without mural thrombosis. Electrocardiography and Holter monitoring confirmed the presence of frequent multifocal VA (67540/24 hours) and paroxysmal ventricular tachycardia. An electrophysiology study using the CARTO system (Biosense-Webster Inc, Diamond Bar, Calif) showed the overlapping of the anatomic position of the aneurysm and the arrhythmogenic substrate identified during mapping. Before surgery, the patient was administered antiarrhythmic drugs, including a betablocker, lidocaine, and amiodarone, with minimal effects.

Off-pump coronary artery bypass (OPCAB) was performed via the left internal thoracic artery to the left anterior descending artery, and the saphenous vein was sequentially anastomosed to the diagonal branch, obtuse marginal, and posterior descending arteries. A mattress suture with pledges was placed in the center part of the aneurysm, and an ablation device (Bipolar Ablation System, AtriCure, Inc, West Chester, Ohio) pierced the ventricle wall through

\footnotetext{
From the Department of Cardiac Surgery, Beijing An Zhen Hospital, Capital Medical University, Beijing, China.

This work was supported by the Medical Capital Development Fund (No. 2009-3116).

Disclosures: Authors have nothing to disclose with regard to commercial support. Received for publication May 27, 2012; accepted for publication June 18, 2012; available ahead of print July 16, 2012.

Address for reprints: Cheng-xiong Gu, MD, Department of Cardiac Surgery, Beijing An Zhen Hospital, Capital Medical University, Beijing 100029, China (E-mail: anzhengu@ sina.com).

J Thorac Cardiovasc Surg 2012;144:e101-2

Copyright (c) 2012 by The American Association for Thoracic Surgery

http://dx.doi.org/10.1016/j.jtcvs.2012.06.048
}

the purse. By clamping the full thickness of the ventricle wall, ablation was done in 4 directions forming a cross shape (Figure 1). The ablation was considered successful when the frequency of accidental premature ventricular contraction was less than 1 per minute; cardiac rhythm remained the same with overdrive pacing; VA did not reoccur when sinus rhythm reached 120 to 130 beats/min in response to isoprenaline perfusion. The mattress suture was tied, and the LVA was repaired by linear closure using interrupted mattress stitches and 2 strips of felt for reinforcement. $^{3}$

The patient recovered with no complications. Holter monitoring showed no recurrence of ventricular tachycardia, and total arrhythmia decreased to 872/24 hours. He was discharged on day 10 with no antiarrhythmic medicine.

At the 6-month follow-up, the patient was symptom free with a cardiac function improved to grade II. Holter monitoring showed incidental arrhythmia. Echocardiography revealed an ejection fraction of 0.44 and a left ventricular enddiastolic diameter of $52 \mathrm{~mm}$. The patient has been anginafree for 26 months with increased exercise tolerance.

\section{DISCUSSION}

Linear closure and endoventricular patch plasty, both performed under cardiopulmonary bypass, were commonly used treatments for LVA. In recent years, LVA repair in OP$\mathrm{CAB}$ has been proven to be effective and feasible. ${ }^{3}$

Although aneurysm plasty can significantly improve cardiac function and spontaneous symptoms, long-term follow-up has revealed a high rate of sudden death caused by malignant arrhythmia. ${ }^{1}$ This is because an aneurysm is the structural and physioelectrical basis of malignant VAs. ${ }^{4}$ The presence of surviving myocardial islands, necrotic tissue, and fibrous tissues in the borders between infarct and healthy myocardium leads to increased local autorhythmicity, which in combination with reentrant pathway causes VAs.

In addition to ventricular aneurysm excision, LVA with arrhythmias has been treated with encircling endocardial ventriculotomy, subtotal endocardial scar resection, and encircling endocardial cryoablation, but these procedures may impair cardiac function and increase surgical risks. Furthermore, studies have shown that the key elements, including the reentrant cycle, may be present in the epicardial or subepicardial layers.

For VA surgical treatment, the key is to achieve contiguous transmural lesions; otherwise, VA may reoccur as residual abnormal activation and the reentrance pathway may 


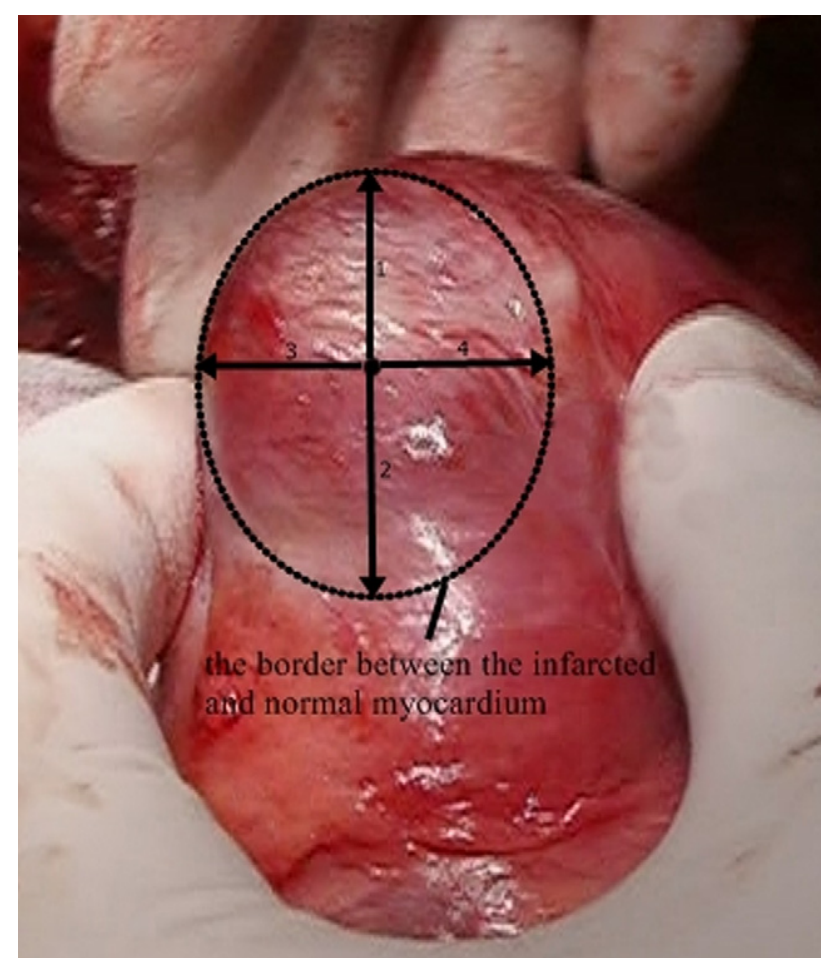

FIGURE 1. Bipolar radiofrequency ablation was performed as a cross shape by clamping the full thickness of the ventricle wall. Two longitudinal lines $(1,2)$ were made parallel to the interventricular groove. The short-axis lines $(3,4)$ were made perpendicular to the longitudinal lines. All the lines extended to the border between the infarcted and normal myocardium.

remain in nontransmural tissue. The bipolar system measures the tissue impedance and adjusts its power output accordingly. Once the impedance reaches a defined threshold, the system automatically terminates the power output, minimizing tissue damage from overablation, and thus protecting the myocardium. ${ }^{5}$ The procedure effectively disrupts reentrant cycles of the ventricular aneurysm, reducing or eliminating VA recurrence.

\section{CONCLUSIONS}

In the case presented, we performed bipolar radiofrequency ablation in addition to LVA placation during OPCAB. Consequently, we not only corrected the structural and functional abnormalities associated with the aneurysm but also provided electrophysiologic treatment and decreased the risk associated with cardiopulmonary bypass, which is particularly important in patients with ventricular aneurysm and poor cardiac function. It is a valuable technique with broad clinical applications, although the medium- and long-term efficacy of this method remain to be determined.

\section{References}

1. Matthias Bechtel JF, Tolg R, Graf B, Richardt G, Noetzold A, Kraatz EG, et al. High incidence of sudden death late after anterior LV-aneurysm repair. Eur J Cardiothorac Surg. 2004;25:807-11.

2. Samore NA, Imran Majeed SM, Kayani AM, Bhalli MA, Shabbir M. Outcome of radiofrequency catheter ablation as a non-pharmacological therapy for idiopathic ventricular tachycardia. J Coll Physicians Surg Pak. 2009;19:548-52.

3. Yu Y, Gu CX, Wei H, Liu R, Chen CC, Fang Y. Repair of left ventricular aneurysm during off-pump coronary artery bypass surgery. Chin Med. 2005;118:1072-5.

4. Tada H, Kurita T, Ohe T, Shimizu W, Suyama K, Aihara N, et al. Clinical and electrophysiologic features of idiopathic left ventricular aneurysm with sustained ventricular tachycardia. Int J Cardiol. 1998;67:27-38.

5. Voeller RK, Zierer A, Lall SC, Sakamoto S, Schuessler RB, Damiano RJ Jr. Efficacy of a novel bipolar radiofrequency ablation device on the beating heart for atrial fibrillation ablation: a long-term porcine study. J Thorac Cardiovasc Surg. 2010;6:203-8

\section{Percutaneous embolization of patent intercostal artery causing persistent type II endoleak and sac enlargement of thoracoabdominal aneurysm 2 years after hybrid repair}

Firas F. Mussa, MD, MS, FACS, Thomas S. Maldonado, MD, FACS, and Charles F. Schwartz, MD, FACS, New York, NY

From the Cardiac and Vascular Institute and Aortic Disease Center, New York University School of Medicine, New York, NY.

Disclosures: Authors have nothing to disclose with regard to commercial support. Received for publication April 22, 2012; revisions received May 27, 2012; accepted for publication June 18, 2012; available ahead of print July 23, 2012

Address for reprints: Firas F. Mussa, MD, MS, FACS, Division of Vascular and Endovascular Surgery, Aortic Disease Center, New York University School of Medicine, 530 First Ave, Suite 6F, New York, NY 10016 (E-mail: firas.mussa@ nyumc.org). J Thorac Cardiovasc Surg 2012;144:e102-6

$0022-5223 / \$ 36.00$

Copyright (C) 2012 by The American Association for Thoracic Surgery http://dx.doi.org/10.1016/j.jtcvs.2012.06.056
Hybrid repair of thoracoabdominal aortic aneurysms has been shown to be safe and effective in properly selected patients. ${ }^{1}$ The operation is a major undertaking, however, and the risks of major complications is real. Among the less reported complications is type II endoleak after such repair. This report underscores the management of a type II endoleak from an intercostal artery causing sac enlargement that was treated by direct percutaneous puncture of the endoleak nidus and coil embolization of the feeding artery. 